\title{
ANTES DE LEER LOS QUARENTA CANTOS DE ALONSO DE FUENTES: PORTADAS, DEDICATORIAS Y LICENCIAS EN EDICIONES DEL SIGLO XVI
}

\author{
Virginie Dumanoir \\ Université Rennes 2 (Francia) \\ virginie.dumanoir@univ-rennes2.fr
}

Como trabajo previo a la edición del Romancero de corte de transcripción manuscrita hasta mediados del siglo XVI, es imprescindible estudiar también los cancioneros impresos contemporáneos, tanto para la elaboración del corpus y la transcripción de los poemas como para el conocimiento del contexto cultural y económico de la afirmación del género romanceril ${ }^{1}$. Nos centramos sobre todo en el campo de la poesía impresa antes del Cancionero de romances de $1546^{2}$, pero es también de interés abarcar los Quarenta cantos de diversas y peregrinas historias, declarados y moralizados, por el magnifico caballero Alonso de Fuentes, impresos en 1550 en Sevilla': la obra de

* Este trabajo se enmarca en el proyecto Cancionero, Romancero y Fuentes Impresas del Ministerio de Economía, Industria y Competitividad (FFI2017-86313-P), financiado por la Agencia Estatal de Investigación (AEI) y el Fondo Europeo de Desarrollo Regional (FEDER), cuyo principal investigador es Josep Lluís Martos.

${ }^{1}$ Podemos hablar de «interacción entre el género romanceril y la imprenta. Limitándonos a las huellas escritas impresas del corpus romanceril de finales del siglo XV y principios del XVI, asistimos al paso progresivo de una forma poética disfrazada de corte hacia un género poético apto para renacer como fenómeno editorial». Virginie Dumanoir, «De un impreso a otro: variatio y errata romanceriles», en $L a$ poesía en la imprenta antigua, ed. de Josep Lluís Martos, Alicante, Universidad de Alicante, 2014, pp. 267-290. Cita p. 287. Véase también al respecto Alejandro Higashi, «El género editorial y el Romancero», en Lemir, 17 (2013), p. 37-84.

${ }^{2}$ Nos referimos así al llamado Cancionero de romances sin año, conservado en dos ejemplares, uno en la Bibliothèque nationale de France (Reserve 8-BL-16099) y otro en la Biblioteca Nacional de España (R/8415). La fecha de esa princeps fue concretada en 1546 por Josep Lluís Martos, «La fecha del Cancionero de romances sin año», en Edad de Oro, 36 (2017), pp. 137-157.

${ }^{3}$ El título completo incluye la mención del destinatario, al ser los cantos «dirigidos al Ilustrísimo y excelente señor don Perafan de Ribera, Marqués de Tarifa». En adelante, nos referiremos a esa obra con el título abreviado de Quarenta cantos. 
Fuentes permite observar cómo un hombre culto 4 de mediados del siglo XVI acompañó el material poético de comentarios personales en prosa, repartidos entre dos cartas iniciales y las glosas explicativas de los «cantos», que son de hecho «romances», después de situar su creación dentro del prestigioso linaje de Alfonso X el Sabio, a quien atribuye también un texto. Nos interesaremos por el modelo editorial de los Quarenta cantos, a partir del análisis del peritexto - títulos, subtítulos e informaciones comerciales de la portada-y del paratexto - carta dedicatoria- en distintas ediciones del siglo XVI. Observaremos así qué lugar ocupa entre las compilaciones romanceriles que se multiplican a partir del primer Cancionero de romances de Martín Nucio.

La existencia de varias reediciones de los Quarenta cantos muestra que podemos considerarlos como un éxito de venta. De hecho, después de 1550, se vuelve a imprimir la obra tres o cuatro veces en el siglo XvI: ¿en 1557?, en 1563, en 1564 y en 1587, en varias ciudades -Sevilla, Alcalá dos veces, Granada y Zaragoza- lo que evidencia la difusión de la obra en distintos puntos de la Península. Hasta ahora se han identificado unos cuarenta y cinco ejemplares ${ }^{5}$ repartidos entre grandes bibliotecas del mundo, con variaciones de títulos, impresores y formatos, pero siempre designados como obras de Alonso de Fuentes. Son cinco los ejemplares conservados de la primera, no los hay de la segunda y serían tres los de la tercera, catorce -o tal vez dieciséis- de la cuarta y 23 o 24 de la quinta: las últimas cifras, en aumento, pueden leerse como consecuencia de una cantidad mayor de libros puestos en circulación. Reproducimos a continuación los títulos originales, con indicación de los datos de la edición que figuran en las portadas:

1550. Quarenta cantos de diversas y peregrinas historias, declarados y moralizados por el magnifico cauallero Alonso de Fuentes.

Sevilla, en casa de Dominico de Robertis ${ }^{6}$.

\footnotetext{
${ }^{4}$ El libro de los Quarenta cantos no es la primera obra de Alonso de Fuentes. De 1547 es su Suma de filosofia natural en la cual asimismo se trata de astrología y astronomía et otras ciencias, impresa en Sevilla por Juan de León. En ella manifiesta sin lugar a dudas la curiosidad, capacidad de reflexión y ganas de compartir conocimientos que se suelen asociar con la élite culta castellana. Se conservan 23 ejemplares de la edición, localizados por Alexander S. Wilkinson en Iberian Books. Books Published in Spanish or Portuguese or on the Iberian Peninsula before 1601 - Libros ibéricos. Libros publicados en español o portugués o en la Península ibérica antes de 1601, Leiden-Boston, Brill, 2010, p. 365.

${ }^{5}$ Wilkinson, ob. cit., pp. 365-366 atribuye siglas a las distintas impresiones, en función de las fechas: IB9239 (1550), IB9240 (1557), IB9241 (1963), IB9242 (1964) e IB9243 (1587). Indica él 35 ejemplares, además de los dos que se conservarían en la Biblioteca de la Hispanic Society y del que se encontraría en Cambridge.

${ }^{6}$ Los cinco ejemplares conservados están en la British Library de Londres (C.63c.30), en la BNE (Madrid) con las signaturas R/6588 y R/31883, en la Fundación Lázaro Galdiano (Madrid) en la serie Z, en la BnF (París), con la signatura RES-YG-781 y en la Hispanic Society (Nueva York).
} 
¿1557? Libro de los quarenta cantos en verso y prosa.

Alcalá de Henares, sin indicación de impresor. ${ }^{7}$

1563. Libro de los quarenta cantos que compuso el magnifico cauallero Alonso de Fuentes, natural de la ciudad de Seuilla, diuididos en quatro partes. La primera es de Hystorias de la sagrada Scriptura. La segunda de hechos Romanos. La tercera de casos de diuersas nasciones. La quarta de Hystorias de Christianos, cōn las cosas que acaescieron en la conquista de Malaga y Granada. [...] Agora nueuamente corregido y ennmendado y con licencia Impresso.

Granada, Emprenta de Antonio de Lebrixa y Garcia de Briones ${ }^{8}$.

1564. Libro de los quarenta cantos pelegrinos que compuso el magnifico cauallero Alonso de Fuentes, natural de la ciudad de Seuilla, divididos en quatro partes. La primera es de historias de la sagrada sriptura. La segunda de hechos Romanos. La tercera de casos de diversas naciones. La quarta de historias de Christianos, con las cosas que acaescieron en la conquista de Malaga y Granada.

Zaragoza, en casa de Juan Millán, impresor de libros?.

${ }^{7}$ No se pudo encontrar ningún ejemplar de esa edición de 1557, lo que lleva a Antonio Rodríguez-Moñino a declarar que «sería ésta la segunda edición, si no confundió la fecha [por 1587] Nicolás Antonio» (La Silva de romances de Barcelona, 1561. Contribución al estudio bibliográfico del romancero español en el siglo XVI, Salamanca, Universidad de Salamanca, 1969, p. 359). El título figura en el catálogo que realizó Nicolás Antonio en el siglo xviII. Como primera de las obras de Alonso de Fuentes -o Alphonsus de Fuentes en la versión latinizada-, indica el «Libro de los quarenta Cantos en verso y prosa. Compluti 1557. 8. \& Granatae in officina Antonii Nebrissensis, \& Garsiae de Briones 1563. 8. [...] \& Caesaraugustae apud Joannem Emilianum 1564» (Bibliotheca Hispana Nova, Madrid, Joaquín Ibarra, 1783, t. 1, pp. 24-25). Notamos que no menciona la princeps de 1550 y que junta la supuesta de 1557 con las de 1563 y 1564, sin indicar cambios de títulos. Julián Martín Abad insiste por su parte en la imposibilidad de encontrar un ejemplar fechado en 1557, excluyendo la idea de que se conservara en la biblioteca de la Hispanic Society. Véase La imprenta en Alcalá de Henares (1502-1600). Introducción a la «Tipología Española» de José Simón Díaz, Madrid, Arco/Libros, 1991, vol. 2, p. 665. En su tesis doctoral, María Cristina González Hernández considera que la mención de una edición de 1557 «podría estar motivada en un error de lectura» (La «Junta de libros» de Tamayo de Vargas: ensayo de documentación bibliográfica, tesis realizada bajo la dirección de Mercedes Fernández Valladares y defendida en la Universidad Complutense de Madrid en 2012, cita p. CLVI). Sin embargo, la portada de la edición de 1587 indica el año con cifras romanas, lo que disminuye la posibilidad de confundir m.d.l.xxxVII con M.D.L.VII. No impide sin embargo la confusión a partir de una catalogación de la edición, en un repertorio que usara cifras árabes y no latinas: un 8 mal dibujado o parcialmente borrado puede parecer un 5 .

${ }^{8}$ Se conserva en la Biblioteca Nacional de España, con la signatura U/8862, reproducido en la Biblioteca Digital Hispánica. También se conserva en la Biblioteka Jagiellonska de Cracovia con la signatura CIM.O.800, en la Biblioteca Universitaria Alessandrina de Roma con la signatura N b 75 y en el Monasterio de Poblet, con la signatura R249-8.

${ }^{9}$ Se conservaron ejemplares en la British Library de Londres (G.11298), en la Biblioteca Nacional de España de Madrid (R/2735, R/9115, R/2322, R/13191 [ejemplar reproducido en la Biblioteca Digital Hispánica] y U/1106), en la Biblioteca de D. Francisco Zabálburu de Madrid (31-54), en la Biblioteca de la Real Academia Española de la Lengua de Madrid (17-VI-23), en la John Rylands University Library 
1587. Libro de los quarenta cantos, que compuso vn Cauallero llamado Alonso de Fuentes, natural de la Ciudad de Seuilla, diuididos en quatro partes. La primera es de Hystorias de la Sagrada Escriptura. La segunda, de los hechos Romanos. La tercera, de casos de diuersas naciones. La quarta, de Hystorias de Christianos. Con las cosas que acaecieron en la conquista de Malaga y Granada. Alcalá, en casa de Juan Gracian que sea en gloria. A costa de Diego Xarami1lo, $1587^{10}$.

No se observa el mismo formato en todas las ediciones. El $4^{\circ}$ privilegiado por Robertis en la princeps de Sevilla (1550) solo se vuelve a utilizar en la de Juan Millán de Zaragoza (1564). Las otras dos eligen el $8^{\circ}$, que corresponde más con la tendencia editorial de proponer libros de tamaño más reducido ${ }^{11}$. Los dos formatos son representativos de dos prácticas editoriales relacionadas con la poesía: por un lado, se multiplican pliegos sueltos en $4^{\circ}$ que favorecen la conservación y amplifican la transmisión de los romances viejos a partir de finales del siglo xv y, sobre todo, después del Cancionero General de Hernando del Castillo de $1511^{12}$; por otro lado, se venden muchos libros de poemas impresos en $12^{\circ}$ en la segunda mitad del siglo XVI, por la comodidad del formato «de faltriquera»: el Cancionero de romances de $1546^{13}$ así como sus reediciones posteriores y las Silvas de romances impresas a partir

de Manchester (R129744), en la Biblioteca General de Navarra de Pamplona (FA/2-188), en la Biblioteca de Menéndez Pelayo de Santander (29.744), en el Monasterio de Poblet (R258-17), en la Biblioteca de la Universidad de Zaragoza (H-12-80) y en la University Library de Princeton (3173.777.358). No pude averiguar las referencias de dos ejemplares más que Wilkinson, ibid., señala en la University Library de Cambridge y en la Hispanic Society de Nueva York

${ }^{10}$ Se conservaron ejemplares en la Biblioteca de Cataluña de Barcelona (Esp. 52, $8^{\circ}$, en la Public Library de Boston (D.150.22), en la St Catharine's College Library de Cambridge (JS/V/1028), en la Houghton Library of Harvard University de Cambridge (EEUU), con la signatura Span 4870.2.32*, en la Biblioteca Nacional de Portugal de Lisboa (RES 41072 P), en la British Library de Londres (11450. aaa.38), en la Biblioteca Nacional de España de Madrid (R/12003, R/6332, R/4690, R/3283, R/28150, R.27255 [ejemplar reproducido en la Biblioteca Digital Hispánica], U/11075 y R/27210), en la biblioteca de la Fundación Lázaro Galdiano de Madrid (Inv. 2918), en la biblioteca de la Real Academia Española de la Lengua (34-V-20), en la Bayerische Staatsbibliothek de Múnich (P.o.hisp. 85), en la biblioteca de la Universidad de Oviedo (CEA-436), en la Bibliothèque nationale de France de París (YG-3264), en la Biblioteca nazionale centrale Vittorio Emanuele II de Roma (8. 56.A.19), en la biblioteca de las Facultades de Filología y Geografía e Historia de Sevilla $(\mathrm{Ra} / 111)$, en la biblioteca de la Universidad de Sevilla (FG RA/0111) y en la Österreichische Nationalbibliothek de Viena (*38.Bb.75). No pude averiguar las referencias de la edición de la Hispanic Society de Nueva York indicada por Wilkinson, ibid.

${ }^{11} \mathrm{Al}$ estudiar la aparición de formatos más reducidos como el $8^{\circ}$, Higashi, art. cit., p. 39, indica que «El nuevo formato daría una constitución manejable a las obras y precios más accesibles».

${ }^{12}$ Vicenç Beltran habla de un «capítulo enteramente nuevo casi contemporáneamente a la edición de Hernando del Castillo: la publicación, entre 1511 y 1515, por el sevillano Jacobo Cromberger, de un manojo de romances en otros tantos pliegos sueltos», El romancero: de la oralidad al canon, Kassel, Reichenberger, 2016, p. 79.

${ }^{13}$ Lo podemos comprobar en el ejemplar conservado en la Biblioteca Nacional de España con la signatura R-8415. Ramón Menéndez Pidal eligió el $8^{\circ}$ en su edición facsímil de 1945 pero conservó el 
de 1550 , lo confirman ${ }^{14}$. Los Quarenta cantos no reúnen solo poesía, sino también comentarios en prosa, lo que dejaría mayor libertad al impresor para elegir entre $4^{\circ}$ y $8^{\circ}$, sin que la extensión de las glosas en prosa permitiera la impresión en $12^{\circ}$. Pudo ser un elemento de decisión el formato en $4^{\circ}$ de otro libro del mismo autor, la Summa de Philosophia natural, impresa en 1547 en Sevilla, por Juan de León ${ }^{15}$. La elección del mismo formato facilitaría la asimilación de los Quarenta cantos con obras más didácticas que recreativas ${ }^{16}$.

A la imposibilidad de asociar un formato único con los Quarenta cantos, se añade la dificultad de describir un modelo de portada constante en las cuatro ediciones de las cuales podemos estudiar ejemplares: 1550, 1563, 1564 y 1587. De hecho, dos presentan el título enmarcado por cuatro orlas xilográfica muy trabajadas y las otras dos carecen por completo de orlas, en función de los formatos: las portadas de 1550 y 1564 contienen grabados, ambas en $4^{\text {o }}$; las de 1563 y de 1587 , en $8^{\circ}$, están despojadas de elementos ilustrativos. Es interesante estudiar en detalle su materialidad, empezando por la princeps.

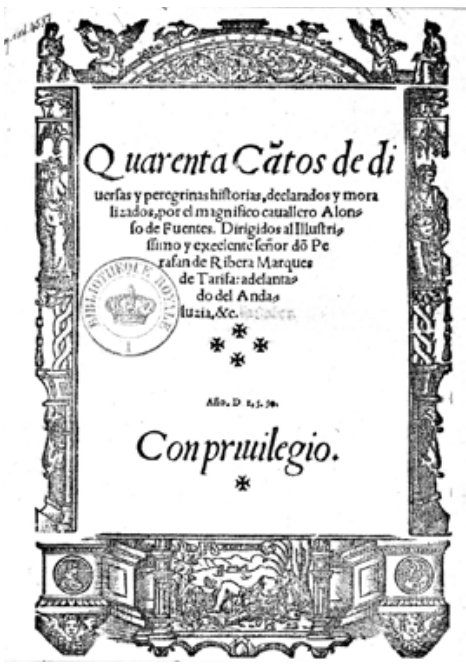

Figura 1

tamaño original del texto, incluso en su introducción, aumentando los márgenes: véase Cancionero de romances impreso en Amberes sin año, ed. e intr. de Ramón Menéndez Pidal, Madrid, CSIC, 1945.

${ }^{14}$ Las ediciones facsímiles más recientes no adoptan el $12^{\circ}$ original, pero sí lo materializan, después del estudio preliminar, contrastando el color del facsímil más oscuro con la página blanca de la edición contemporánea. Véase la Primera parte de la Silva de varios romances. 1550, ed. e intr. de Vicenç Beltran, México, Frente de Afirmación Hispanista, 2016, así como la Segunda parte de la Silva de varios Romances. 1550, ed. e intr. de Vicenç Beltran, México, Frente de Afirmación Hispanista, 2017.

${ }^{15}$ La edición de 1547 fue conservada en más de treinta ejemplares, entre los cuales podemos destacar siete de la Biblioteca Nacional de España (R/8163, R/11911, U/5078, R/4553, R/5841, R/2217 y R/6659) que servirán de base a estudios posteriores de las glosas y de los comentarios.

${ }^{16}$ En otro trabajo desarrollaremos este punto. 
La portada podría ilustrar lo que Miguel Ángel Pérez Priego llama «un ejemplo de edición de poca calidad, llevada a cabo en una imprenta que utilizaba materiales reusados ${ }^{17} \gg$. De hecho, las cuatro partes de la orla coinciden relativamente bien en la parte superior, pero no tanto en la inferior, donde la pieza baja presenta una rotura que deja un blanco más importante a la izquierda que a la derecha. Además, la orla inferior no está centrada perfectamente. El título en letra carolina está dispuesto en forma de pirámide inversa sin que los cortes de las palabras estén señalados con regularidad. Una doble barra oblicua aparece después de cuatro de las seis palabras interrumpidas por el paso a otro renglón, sin que se pueda encontrar ninguna lógica ${ }^{18}$. Las primeras palabras destacan por ser de tamaño mayor, pero se utiliza la forma abreviada «Cātos», lo que deja también en la primera línea el «de» seguido de la primera sílaba de «diversas», cuando era posible colocar solo Quarenta cantos en la primera línea, para darle más relieve ${ }^{19}$. Además, el tamaño de las letras hace corresponder el principio del título con la mención final «Con privilegio», que no entrega una información de la misma naturaleza. El año está indicado en cifras árabes y letra pequeña. Entre el título y la indicación del año figuran cuatro cruces de Malta y otra ocupa la última línea, debajo de «con priuilegio». Faltan los detalles de la imprenta, que se tienen que buscar en el colofón, aunque no esté ocupado todo el espacio delimitado por las cuatro piezas de la orla.

A pesar de no encajar totalmente, las piezas xilográficas confieren a la página cierto carácter monumental, por el aspecto arquitectónico del conjunto que recuerda ediciones prestigiosas del taller vecino de los Cromberger $^{20}$. Las columnas verticales son casi simétricas en su mitad inferior en que son ínfimos los detalles de las partes abalaustradas que las distinguen. En cambio, en la mitad superior aparecen dos figuras humanas que podrían ser un hombre a la derecha -con una trompeta rota a su lado- y una mujer con el pecho medio desnudo a la izquierda - ¿llevando un ramillete?-, ambos mirando hacia

\footnotetext{
${ }^{17}$ Miguel Ángel Pérez Priego, La edición de textos, Madrid, Síntesis, 2011, p. 240.

${ }^{18}$ No se puede atribuir a un lector del libro, que habría añadido las rayitas con su pluma, porque figuran iguales en los ejemplares de la Biblioteca Nacional de Madrid y de la Bibliothèque Nationale de France.

${ }^{19} \mathrm{Si}$ comparamos con la portada del Cancionero de romances de 1546, observamos que las palabras «Cancionero de» están escritas en tamaño menor, lo que permite poner de realce, sola y en letra mayor, la palabra «Romances». Martín Nucio juega también con mayúsculas y minúsculas, lo que no se observa en la primera edición de los Quarenta cantos de Fuentes.

${ }^{20}$ Véase James P. R. Lyell, La ilustración del libro antiguo en España, ed. de Julián Martín Abad, Madrid, Ollero y Ramos, pp. 205 y 207, en que las figuras 125 y 126 propuestas para representar el trabajo de los Cromberger presentan una portada ricamente orlada parecida a la de las ediciones de 1550 y 1587 de los Quarenta cantos.
} 
los márgenes con la cabeza levemente inclinada. Terminan ambas columnas por sendos doseletes, cuya arquitectura presenta también variantes, además de una rotura en la parte alta del de la izquierda. ¿Pertenecen a un libro religioso en que ilustraban Adán y Eva? Está clara la temática religiosa, si nos fijamos en la pieza xilográfica inferior. Las bases arquitectónicas cuadradas en el primer plano abren la perspectiva de un templo, con la presencia de otras columnas más pequeñas. Ambas descansan en una figura de ángel y están adornadas con bustos de cariz antiguo, uno de pelo más largo a la derecha y otro de pelo más corto a la izquierda. Parecen mirar hacia el cielo o al personaje central tumbado con la cabeza apoyada en la mano. Arriba del todo, detrás de la figura pensativa - ¿de san Jerónimo? ¿de ermitaño? ¿de Job?-y, más allá de un castillo perdido en un paisaje lejano y montañoso, una filacteria cruza el cielo, con las palabras «Memento mori». La pieza superior presenta un arco de motivos vegetales rodeado de cuatro figuras angelicales. En el centro, perdido entre los arabescos adivinamos una figura con el brazo derecho estirado, como si enseñara algo a su derecha, pero la cabeza hacia su izquierda, en una postura que suele atribuirse a Dios en cuadros y pinturas murales representando la Creación bíblica. En las esquinas superiores están sentados dos personajes, uno leyendo y el otro escribiendo ${ }^{21}$. Se están acumulando símbolos religiosos, pero también elementos relacionados con la cultura antigua, musical y con el ámbito del libro, acorde con el propósito didáctico de un libro de «cantos declarados y moralizados $\left.{ }^{22}\right\rangle$.

\footnotetext{
${ }^{21}$ Casi la misma portada orlada se observa en un pliego - también en $4^{\circ}$ - conservado en la Biblioteca Nacional de Lisboa, con la signatura Res. 218 V, catalogado como 259 Y 260 en Antonio RodríguezMoñino, Nuevo diccionario bibliográfico de pliegos sueltos poéticos siglo XVI, ed. corregida y actualizada por Arthur L.-F. Askins y Víctor Infantes, Madrid, Castalia, 1997, p. 302: «Se unifican las dos entradas ns. 259 y 260, por tratarse de dos ejemplares del mismo pliego. Jaime Moll, en 1994, p. 250 lo atribuye al taller sevillano de Andrés de Burgos». Véase Jaime Moll, «De libros y Bibliotecas», en Homenaje a Rocío Caracuel, Sevilla, Universidad de Sevilla, 1994, pp. 205-216. Llama la atención el parecido del grabado utilizado en el pliego de Lisboa, pero el dibujo se ha simplificado e invertido simétricamente, siguiendo un eje horizontal, combinándolo además con otro tipo de columnas desprovistas de figuras. La filacteria aparece también, pero en blanco. Para el estudio de las fechas y de los impresores de los pliegos conservados en Lisboa, véanse los Pliegos Poéticos Españoles de la Biblioteca Nacional de Lisboa, ed. de María Cruz García de Enterría, Madrid, Joyas Bibliográficas, 1975, pp. 25-30. En el apartado dedicado al pliego n. ${ }^{\circ} 10$, subraya «la bella orla plateresca» $y$, en el espacio dibujado por las orlas, tres tacos figurando dos hombres y un árbol, antes de indicar el título en letra gótica: «Romance de las notables cosas que tiene la imperial ciudad de Toledo: nueuamente añadido por Luys Hurtado contrahecho al que dize. "Miraua de campo viejo"» (p. 149).

${ }^{22}$ También podría corresponder con el ámbito de los pliegos que divulgaban los comentarios del Libro de Job, como Las lectiones de Job trobadas por un devoto religioso de la orden de los predicadores. Con un infierno de dañados, impreso en el taller sevillano de Estacio Carpintero en 1545. Se conserva un ejemplar en la Biblioteca Nacional de España, con la signatura R/1740. En el Nuevo diccionario..., ob. cit., p. 727, recibe el n. ${ }^{\circ} 933$.
} 
La segunda portada orlada corresponde con la edición de 1564, impresa en Zaragoza en casa de Juan Millán. Presenta numerosas marcas de desgaste, sobre todo en las columnas verticales y en la pieza inferior, lo que deja suponer que no se está utilizando por primera vez.

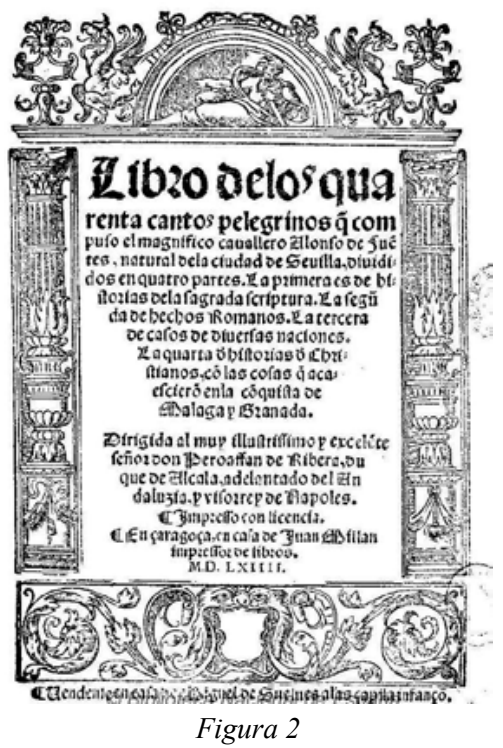

El título está escrito en letra gótica rotunda y destacan las dos primeras líneas por la utilización de tipos gruesos en la primera, algo menores en la segunda. A partir de la tercera línea, se utiliza el mismo tipo, pero en tamaño menor aún. Como en la portada de la edición de 1550, las palabras destacadas por su tamaño no forman una oración completa, puesto que son «Libro de los qua» y si asociamos las dos líneas de letras mayores, leemos «Libro de los qua / renta cantos pelegrinos q com». Ambas combinaciones no son las más cuidadas, como lo subraya el uso del signo tironiano para abreviar «que» y la grafía «pelegrinos» $»^{23}$. El uso del signo tironiano dentro del apellido Fuentes es otra señal de posible negligencia en la composición. También podemos mencionar la ruptura del género entre el título que anuncia un libro y el participio «dirigida». Tampoco parece perfecta la disposición del texto en el folio. El texto está llenando la casi totalidad del espacio delimitado por las piezas xilográficas, formando dos bloques distintos: el primero con el título y detalle de las cuatro partes, el segundo con información del destinatario,

${ }^{23} \mathrm{El} D R A E$ indica que la palabra es vulgar y poco usada. No figura en el Diccionario de Autoridades ni en Martín Alonso, Diccionario medieval español, Salamanca, Universidad Pontificia de Salamanca, 1986. 
de la licencia, de la imprenta, de la ciudad y de la fecha, dejando fuera del marco, debajo de la orla inferior, la indicación del lugar en que se vende la obra. Dicha frase habría podido ir junta con las demás informaciones de tipo comercial al elegir el tipógrafo tipos más reducidos para la primera línea, o para el detalle de las partes, o para el segundo bloque. De hecho, parece que el tipógrafo no se dio cuenta hasta el final de que le iba a faltar espacio y que no quiso volver a componer la portada, dejándola imperfecta.

En cuanto a la orla, como en la edición de 1550, permite dar a la obra cierto relieve, a pesar de las errata. La parte superior presenta un arco rodeado de arabescos formando quimeras y motivos florales en parte simétricos. Debajo del arco está un personaje masculino con barba y pelo semilargo, con el brazo derecho extendido y la cabeza inclinada en dirección contraria, en la misma postura ya observada en la figura borrosa situada en el arco de la portada de 1550. Sin embargo, en la portada de 1564, es el único personaje antropomórfico. En las columnas no se representan seres humanos, ni bustos, ni retratos. En la orla inferior, la boca de un león rugiendo dibuja la forma de un escudo sin armas, rodeado de vegetación entrelazada. Los mismos grabados formando un cuadro se encuentran en el segundo folio de la edición de la Theorica de virtudes en coplas y con comentario. Compuesta por don Francisco de Castilla, y otras obras en metro que son las que en la siguiente hoja se contienen, impresa también en Zaragoza, pero por Agostín Millán, en $1552^{24}$. Los grabados no muestran en esa edición el desgaste observable en los Quarenta cantos de 1564, con lo cual es de suponer que fueron diseñados para la Theorica de virtudes o para otro libro muy cercano, y no para los comentarios de Alonso de Fuentes.

Las portadas de las ediciones de 1563 y 1587, relativamente austeras, recuerdan las de los cancioneros de romances en las cuales los escasos dibujos, cuando los hay, remiten a las rúbricas de los impresore ${ }^{25}$ más que a un deseo de atraer la atención de un potencial lector con una ilustración adecuada al contenido de la obra. Ya por su formato de $8^{\circ}$, no permiten integrar orlas, $\mathrm{y}$ menos aún por la amplitud del título desarrollado que no se abrevia para

${ }^{24}$ No se trata de la primera edición de la obra de Francisco de Castilla, que sale de la imprenta de Gorge Costilla en 1518, y de la cual se conservan tres ejemplares en la Biblioteca Nacional de España: R/8050(1), R/8537(1) y R/12194. La de Agostín Millán es pues la segunda edición conocida. Se conservan cinco ejemplares en la Biblioteca Nacional de España: R/2179, R/2338, R/2345, R/2362 y R/11771. Es de notar que el formato de la obra de Castilla es el $4^{\circ}$, como la edición de 1564 de los Quarenta cantos. La posibilidad de reutilizar las orlas pudo determinar el formato, tal vez porque comparten ambos libros el verso, el comentario y el propósito moralizador.

${ }^{25}$ Remito a las marcas y escudos de los impresores españoles. Véase José Manuel Martín y Víctor Infantes, La rúbrica impresa de los libros españoles del siglo XVI, Madrid, Turpin editores, 2015. 
caber mejor en un libro de bolsillo. Los tipos elegidos son romanos, sin capitales adornadas.
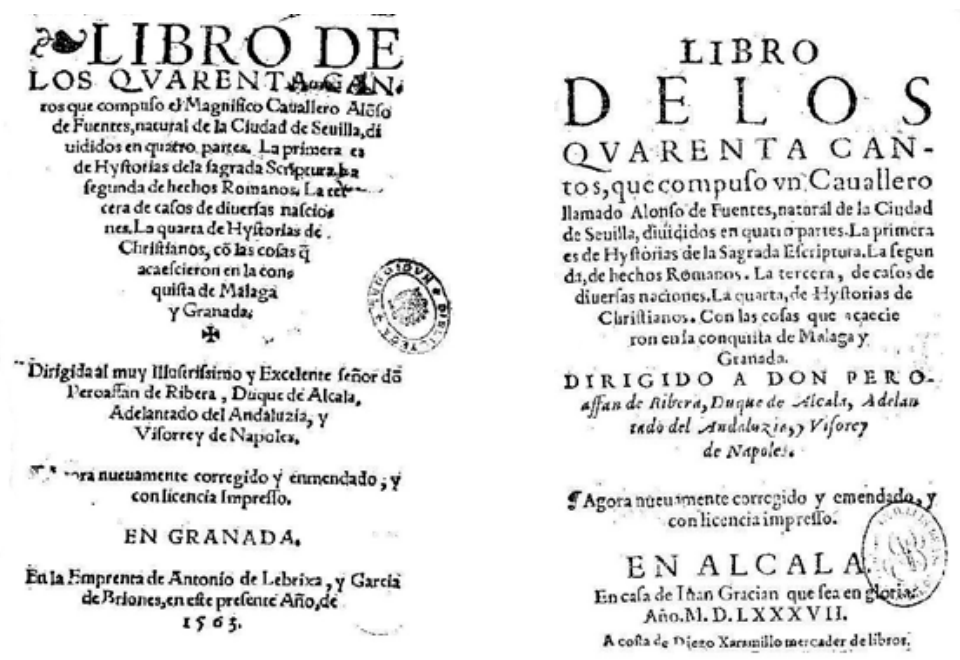

Figuras 3 y 4

Los únicos detalles ilustrativos figuran en la portada de 1563 en que son más funcionales que decorativos: el elemento vegetal permite centrar la palabra «Libro», y la diminuta cruz de Malta marca el final del título. En ambas portadas se adopta el título de Libro de los quarenta cantos, preferido a Quarenta cantos en la portada de 1550 . Se distinguen así de los pliegos sueltos en los cuales no se suele utilizar la palabra «libro ${ }^{26} »$, sino la cantidad y el género de los textos ${ }^{27}$. El título de la edición de 1563 es más amplio y conserva unas particularidades ortográficas presentes en portadas anteriores, como es «scriptura», «nasciones», «emprenta» y el género equivocado de «dirigida». Todas se corrigen en la portada de 1587, en la que la única forma arcaizante es «emendar». Como en las ediciones de 1550 y 1564, la elección del tamaño de los tipos no parece del todo ideal, aunque sea mejor en la de 1587. Si leemos el texto subrayado por los tipos mayores en la portada de

${ }^{26}$ El Nuevo Diccionario..., ob. cit., n. ${ }^{\circ} 935,935.5$ y 936, p. 727-729, solo contabiliza tres ejemplares del Libro en el cual se contienen cincuenta romances con sus villancicos y desechas. Notamos entonces que la compilación supera la amplitud habitual de los pliegos y anuncia, por lo menos en su versión inicial, diez romances más que los Quarenta cantos.

${ }^{27}$ Muchos pliegos están encabezados por «Aquí comiençan» seguido de la indicación de la cantidad de textos romanceriles contenidos, como es el caso, entre otros muchos, de «Aquí comiençan ciertos romances» (ibid., n. ${ }^{\circ} 654$, p. 551-552), «Aquí comiençan cinco romances» (ibid., n. ${ }^{\circ} 655$, n. ${ }^{\circ} 656$, n. ${ }^{\circ}$ 657, pp. 552-554), «Aquí comiençan diez maneras de romances» (ibid., n. ${ }^{\circ} 658$, p. 554-555). Otro tipo de título es más escueto: «Tres famosísimos romances» (ibid., n. ${ }^{\circ} 1094.3$, n. $^{\circ} 1094.5$ o n. ${ }^{\circ} 1095$, p. 819-820). 
1564, corresponde con «Libro de los quarenta can». En la de 1587, a pesar de la mezcla de mayúsculas, minúsculas y tamaños distintos, las palabras que sobresalen son «Libro / de los / quarenta can / tos, que compuso vn Cauallero», lo que permite disponer de las informaciones básicas, aunque queden incompletas.

Si nos interesamos por los nombres mencionados en la portada, notamos que la de la princeps no identifica al impresor. Dominico de Robertis se nombra solo en el colofón de la obra, con lo cual no imita el modelo del Cancionero de romances de 1546, en que Martín Nucio desempeña un papel notable, al asumir él el prólogo encabezado por el título «El impresor» ${ }^{28}$. Puede sorprender que Dominico de Robertis y su sucesor no imitaran «el nuevo formato para la publicación de romances» ofrecido por Nucio. Es tanto más original cuanto que las ediciones romanceriles que se multiplicaron a partir de la segunda mitad del siglo $\mathrm{XVI}^{29}$ adoptaron el nuevo modelo editorial: la segunda edición del Cancionero de romances de 1550 como las primeras Silvas de varios romances del mismo año. Es cierto que, en el caso de Dominico de Robertis, el colofón completa la identificación del impresor con «difuncto, que Dios aya»: si pudo participar en la elaboración de la obra, se trataría de una de sus últimas realizaciones ${ }^{30}$. A su sobrino Pedro de Luján, que le hereda el taller y sigue imprimiendo algún tiempo con el sello de su tío, se le conoce por ser autor de dos obras en prosa y con marcada ambición didáctica ${ }^{31}$, lo

\footnotetext{
${ }^{28}$ Véase las primeras palabras que subrayan la labor de compilación del Cancionero de romances, en R-8415, f. 1r: «He querido tomar el trabajo de juntar en este cancionero todos los romances que han venido a mi noticia». Para el comentario de ese prólogo, véase Virginie Dumanoir, «El corpus del romancero cortés manuscrito: los límites del género», en Pragmática y metodologías para el estudio de la poesía medieval, ed. de Josep Lluís Martos y Natalia A. Mangas, Alicante, Universidad de Alicante, 2019, pp. 211-234.

${ }^{29}$ «Pone con ello un corpus amplio de textos que antes circulaban en pliegos sueltos a disposición de un grupo de consumidores interesados en el romance como género, pero no en el pliego suelto como formato editorial, dada su distancia geográfica de los principales centros impresores españoles. Avecindado en Amberes y acostumbrados más al libro que al pliego, se trata de un público que parece más familiarizado con el libro de bolsillo (en dozavo) para una selección amplia y organizada de romances, lo que al final concluirá con el romancero como un género editorial», Higashi, art. cit., p. 87.

${ }^{30}$ Joaquín Hazañas y la Rúa, en un libro también publicado como obra póstuma, indica que Dominico de Robertis figura como impresor, heredero del taller de su padre, a partir de 1534, y que «falleció a fines de 1548 o principios de $1549 »$ », lo que coincide con los datos del colofón de la primera edición de los Quarenta cantos. Véase Joaquín Hazañas y la Rúa, La imprenta en Sevilla. Noticias inéditas de sus impresores desde la introducción del arte tipográfico en esta ciudad hasta el siglo XIX, Sevilla, Junta de Patronato del Archivo y Sección de Publicaciones de la Excma. Diputación Provincial de Sevilla, 1949, vol. 2, apartado dedicado a «Dominico de Robertis».

${ }^{31}$ Don Silves de la Selva de Pedro de Luján (Sevilla, Dominico de Robertis, 1546). Guía de lectura, ed. e intr. de María Isabel Romero Tabares, Alcalá de Henares, Centro de Estudios Cervantinos, 2004, p. 8: «A Luján se le conoce especialmente por ser el autor de Coloquios matrimoniales, un libro destinado a la educación de las mujeres que conoció catorce ediciones desde su aparición» y la filosofía elaborada en sus Coloquios se prolonga en su continuación del Amadís impreso en 1549. «Don Silves se publica
} 
que confirmaría la orientación hacia un formato conectado con un género serio. El doblete «declarados y moralizados» que acompaña la mención de los cuarenta cantos no deja lugar a dudas acerca de la intención, que dista mucho de la convicción de un impresor como Martín Nucio, que solo entrega textos sin acompañamiento de ningún tipo, deseoso de que los romances impresos sirvan de diversión. Así aparece en las primeras palabras del prólogo:

He querido tomar el trabajo de juntar en este cancionero todos los romances que han venido a mi noticia, pareciéndome que qualquiera persona para su recreación holgaria de lo tener, porque la diuersidad de historias que ay en el dichas en metros y con mucha breuedad sera a todos agradable ${ }^{32}$.

La primacía del placer para el lector se puede leer en la evolución del título de la obra de Fuentes. No podemos ser totalmente afirmativos en cuanto a la fiabilidad de la formulación de Nicolás Antonio para designar la edición de 1557: Libro de los Quarenta cantos en verso y prosa; sin embargo, al referirse a la obra filosófica de Alonso de Fuentes, N. Antonio resulta fiel a los originales conservados, lo que nos invitaría a confiar en él. Si aceptamos la posibilidad de que dicho título sea exacto, la desaparición de «declarados y moralizados» llama la atención, porque también se observa en las ulteriores ediciones de 1563, 1564 y 1587, sin que el contenido del libro cambie, es decir, sin que desaparezca la prosa glosadora. Se acompaña de la aparición del verbo «compuso», que abre dos niveles de lectura: o entendemos que Alonso de Fuentes fue autor del comentario sobre los romances o de la integralidad de la obra, textos incluidos. La última formulación del título, en la edición de 1587, rebaja al «Magnífico Cauallero Alonso de Fuentes» al nivel de «un cauallero llamado Alonso de Fuentes» lo que marca el paso del tiempo así como una posible pérdida de interés del público por los méritos anunciados de los autores.

La misma simplificación se observa en la mención del destinatario de la obra. En la primera edición, se celebra como «Illustrissimo y excelente señor», dotado del doble título de «Marques de Tarifa y adelantado de Andaluzia».

bajo el amparo de la saga de los Amadises, pero [...] se diferencia notablemente de los descendientes del héroe retratados por Feliciano de Silva. El libro de Luján pertenece a ese grupo de libros de caballerías que posee intención didáctica», ibid., p. 9.

${ }^{32}$ En cuanto a Alonso de Fuentes, notamos que es el único autor identificado, a pesar de que no lo sea de la integralidad de la obra. La primera edición de 1550 lo indica sin lugar a dudas, puesto que las primeras palabras del título de la portada anuncian «quarenta cantos de diuersas y peregrinas historias» sin nombre de poeta que pudiera reivindicar la paternidad, para mencionar después cuál fue el papel de Alonso de Fuentes: con «declarados y moralizados», atribuye a Fuentes el papel de comentarista y no de autor, señalando la existencia previa de textos. Ob. cit., f. 1r. 
Notamos cierta inflación en las ediciones de 1563 y 1564 en que se le llama «muy illustrissimo», además de sustituir el título de Marqués por el de «duque de Alcalá», y de añadir el cargo de «Visorrey de Napoles». Por cierto, pertenece dicho marqués a un linaje prestigioso, ya que su abuelo Perafán de Ribera (1340-1425) ya era adelantado mayor de la frontera ${ }^{33}$. En la portada de 1587, solo queda la mención de «don Peroafan de Ribera», con los tres títulos anunciados en las portadas de 1563 y 1564 . El apoyado homenaje de la primera impresión, destinado a alabar a Perafán de Ribera, presentándole como un poderoso mecenas, ya no parece tan necesario en 1587. Per Enríquez Afán de Ribera, llamado Perafán de Ribera, I duque de Alcalá y II marqués de Tarifa, había muerto en Nápoles en 1571, siendo todavía virrey ${ }^{34}$. No desaparece sin embargo la carta dedicatoria inicial que, sin reiterar de manera ostentosa los títulos del destinatario, subraya su poder ${ }^{35}$. En la primera edición, la carta dedicatoria ocupa el recto del segundo folio, pues un lugar destacado. El texto está escrito en letra carolina, con caja de escritura de $5 \mathrm{~mm}$, reutilizada posteriormente para anunciar los «cantos», con lo cual podemos considerar que le da el impresor cierto relieve a las palabras previas de Alonso de Fuentes. La mención de la licencia queda relegada en el colofón que indica que el libro fue impreso «siendo primero visto y examinado, en el Colegio del Sancto Thomas de la dicha ciudad». La carta dedicatoria es pues el primer texto después de la portada. Reproduzco a continuación el texto impreso en la edición de $1550^{36}$.

\section{Yllustrísimo señor ${ }^{37}$.}

No ha mucho tiempo, que un señor a quien yo tenia gran obligacion para seruir, me imbio quarenta (a quien el llamaua Cantos), Mandandome que se los declarase: por ser de diversas y peregrinas historias, y carecer de la noticia

${ }^{33}$ Véase al respecto Fernán Pérez de Guzmán, Generaciones y semblanzas, ed. de José Antonio Barrio, Madrid, Cátedra, 1998, pp. 122-123.

${ }^{34}$ Véase Miguel Ángel Ladero Quesada, «De Per Afán a Catalina de Ribera: siglo y medio en la historia de un linaje sevillano (1371-1514)», en España medieval, 4 (1984), pp. 447-498.

${ }^{35}$ Es de notar que ese poder no se limita a lo político sino que conecta con la imprenta: Payo Enríquez de Ribera, hijo del mencionado en los Quarenta cantos de Alonso de Fuentes, «llevó la primera imprenta en Centro América, desde México a Guatemala», según leemos en Flavio Rivera Montealegre, Genealogía de la familia Montealegre. Sus antepasados en Europa y sus descendientes en América, North América-Internacional, Trafford Publishing, 2012, p. 442.

${ }^{36}$ En notas a pie de página indicamos las variantes ortográficas en las demás ediciones del siglo XVI, con excepción de la de 1557. Modernizamos la $f$ utilizada en la edición de 1550 y explicitamos los signos tironianos. Solo dejamos la abreviatura «V.S.» que comentaremos.

${ }^{37}$ En la versión de 1563 el título se escribe en mayúsculas en caja doble de la del resto de la carta. En la de 1564, se añaden mayúsculas iniciales, también de tamaño doble. El impreso de 1587 suprime «Illustrissimo señor» y lo explicita: «A don Perafan/ de Ribera, Duque de Alcala.\&.» La primera línea está escrita en mayúsculas tres veces mayores que las minúsculas de la segunda línea del incipit, a su vez mayores que el resto de la carta. Podríamos entenderlo como una confirmación de que, en 1587, el público 
de algunas de ella, y yo auiendo començado en ejecucion deste mando $\mathrm{a}^{38}$ hacerlo, quiso dios llevarlo para si antes ${ }^{39}$ que rescibiesse de mi este servicio, el qual tengo entendido que le diera gran contento a cuya causa lo dexe en aquel estado por auer cessado la ocasion que me esforçaua para passar este camino. Despues desto por no perder lo que del tenia andado (no con poca dificultad), procure acabarlo para ofrecerlo a V.S. ${ }^{40}$ illustrissima, por muchas causas, que por que no den de mi nota de lisonja: y por ser a todo el mundo notorias no quiero declarar: baste que las principales que a elo me mouieron podrán alcançar de .V.S illustrissima que resciba este pequeño seruicio con la voluntad quesele ofrece, porque dize Plutharco ${ }^{41}$ (no menos illustra a los grandes señores aceptar y rescebir alegremente los pequeños seruicios que hazer grandes mercedes) y estas serán ${ }^{42}$ para mi no pequeñas en admitir y recebir. V.S. illustrissima debaxo de su amparo esta mi obra porque solo esto le puede dar el Ilustre, y credito que el caudal de mi entendimiento no pudo cumplir. Porque quien dexara de tener todo respecto a la obra que ha tomado debaxo de su proteccion, el entendimiento ${ }^{43}$ de V.S. illustrissima, cuya vida y illustrissimo estado nuestro señor prospere y aumente ${ }^{44}$ a su sancto seruicio ${ }^{45}$.

Las variantes observables en las posteriores ediciones son marginales. No podemos saber cómo fue la de 1557, pero notamos, en las conservadas, una voluntad de subrayar la particularidad de las palabras dedicatorias, con el uso de tipos distintos. La dedicatoria de 1563 está escrita en cursivas carolingias que separan nítidamente las palabras del autor de las del doctor Juan

potencial de la obra necesitaba esa aclaración. También es cierto que los cuatro primeros folios - del f. $1 \mathrm{v}$ al f. 3r-, ocupados por dos licencias, podían introducir cierta ambigüedad acerca de la identidad del «Ilustrísimo señor». Cuando la expresión está en el f. 2r, sin que medie mucho texto ajeno, el lector se puede acordar de quién es el destinatario, porque fue aclarado en la vecina portada. Cuando se intercalan cuatro folios, tres de ellos ocupados por una carta del mismo rey don Felipe, puede ser necesario recordar quién es el destinatario.

${ }^{38}$ La preposición «a» falta en la edición de 1587.

${ }^{39} \mathrm{La}$ edición de 1564 escribe «ante».

${ }^{40} \mathrm{La}$ abreviatura aparece tres veces en las ediciones de 1550 y 1564 , a pesar de ser las dos en $4^{\circ}, \mathrm{y}$ de dejar la de 1564 un espacio en blanco correspondiendo con varias líneas. La edición de 1587 desarrolla «Vuestra Señoría» dos veces, pero mantiene la última fórmula abreviada, lo que coincide con una conservación bastante aleatoria de los tironianos numerosos en la impresión de 1550 . La edición de 1563 desarrolla las tres abreviaturas «V.S.» así como todos los signos tironianos de la carta, con excepción de las cinco últimas líneas.

${ }^{41}$ Como suele pasar, la transcripción del latín da lugar a variantes. En la carta de 1564 se escribe como en la de 1550, pero leemos «Plutarco» en 1563 y «Plutarcho» en 1587.

${ }^{42} \mathrm{La}$ explicitación del tironiano de la princeps da lugar a una desarticulación de la forma verbal en «ser $\bar{a} »(1564)$.

${ }^{43}$ La edición de 1587 escribe «en el entendimiento», lo que impide la comprensión de la frase y manifiesta el descuido o la ignorancia del tipógrafo o del que preparó la edición.

${ }^{44} \mathrm{Se}$ escribe «augmente» en las ediciones de 1563 y 1587.

${ }^{45}$ Quarenta cantos, edición de 1550. 
de Salcedo quien autorizó la impresión ${ }^{46}$. Juan Millán, en la edición de 1564, elige una caja mayor que la de la licencia inicial, sin optar por una que habría utilizado la integralidad del espacio disponible. El tipo es gótico y corresponde así con la portada. La carta de 1587 presenta cierta originalidad, al estar escrita en letra romana como la portada y licencias, pero en letra menor. Son varias las posibles explicaciones: la disminución del interés de dicha dedicatoria después de la muerte del interesado, la voluntad de permitir que quepa la integralidad de la carta en el f. $3 \mathrm{v}$, a pesar del formato en $8^{\circ}$, o la necesidad de manifestar la diferencia de estatuto entre la carta del rey y la de Alonso de Fuentes, con el uso de una caja menor ${ }^{47}$. Lo cierto es que, a pesar del simbolismo asociado con una letra más pequeña, se llama así la atención sobre dicha carta.

En el mismo sentido va el uso de la inicial $N$ adornada, en todas las ediciones de la obra. La $N$ de la princeps está dibujada en un rectángulo, casi un cuadrado, de seis líneas de altura. Es una $N$ blanca, geométrica y sencilla, delante de un ramo de tres flores. El dibujo se ve muy bien, al contrario de la $\mathrm{N}$ de la edición de 1563, bastante borrosa. Está incluida en un cuadrado de cuatro líneas de lado, de fondo que parece vegetal. La $N$ es blanca también, de forma geométrica con algunas púas en la línea oblicua. La inicial de la carta impresa en 1564 está a juego con las columnas de la portada. Está dentro de un cuadrado de cinco líneas de lado, de fondo blanco atravesado verticalmente por una flor. La última edición, de 1587, se distingue por el uso de una $N$ negra y fina dentro de un cuadro con delicados motivos vegetales. El tamaño confirma que no fue diseñado el taco para ese uso, porque no corresponde el lado del cuadrado ni con cuatro, ni con cinco líneas. Sin embargo, podemos subrayar que el impresor utilizó para la inicial de la epístola del mismo autor un taco distinto. Podemos concluir que todos los impresores, al preparar la edición del texto, no solo incluyeron la carta dedicatoria, sino que le dieron cierta importancia con la inclusión de una inicial adornada.

Podría sorprender la conservación de dicha carta, aun después de las fechas en que presentaba una forma de necesidad. De hecho, como lo manifiesta su contenido, lo que se busca en la princeps es el amparo de un hombre poderoso, que dé a la obra «lustre y crédito», así como «protección». La

${ }^{46} \mathrm{El}$ texto de la licencia, en el f. 1v, aparece en carolina algo mayor. Hasta cierto punto, le confiere visibilidad. Sin embargo, notamos que la elección de una caja menor para el texto de la epístola permite que quepa en un solo folio, a pesar del formato $8^{\circ}$.

${ }^{47}$ La última opción es menos convincente, en la medida en que la «Epistola dirigida por el autor a vn cierto señor que le embio estos Cantos, para que se los declarasse: el qual murio antes que se acabasse esta obra», también de Alonso de Fuentes, y que empieza en el recto del f. 4, está escrita con la misma caja de escritura que la carta del rey, de más cómoda lectura. 
continuidad de la mención de Perafán de Ribera en todas las portadas subraya la eficacia del salvoconducto que, por cierto, confirma la buena elección de un destinatario recién promovido, el marqués de Tarifa, que encarna el éxito de los votos formados por Alonso de Fuentes al final de la carta, cuando espera que Dios «prospere y aumente» la vida y los bienes de su protector. Las mismas portadas lo confirman al añadir, a partir de la edición de 1563, el título de «visorrey de Napoles» otorgado por el rey en 1559, a los títulos que acompañan la mención del señor de Ribera. No menciona en cambio ninguna de las ediciones el cargo de virrey de Cataluña, que asumió Perafán entre 1554 y 1558, sin duda porque los impresores remiten al cargo todavía vigente en las ediciones de 1563 y 1564, y al de mayor renombre post-mortem en la de 1587. Pese al prestigio del protector inicial, es evidente que no es suficiente, como lo muestra la necesaria mención de la licencia dada a la impresión de la obra ${ }^{48}$. En la edición de 1563 se añade una declaración de Juan de Salcedo, Provisor y gobernador de Granada, que autoriza la impresión de la obra «porque en el no ay cosa de error». Indica que cumple con la obligación de volver a examinar las obras que ya se habían impreso, sin mencionar la princeps. Lo hace sin embargo en la edición de $1564^{49}$. Otro detalle llama la atención: la fecha del documento firmado por Juan de Salcedo es la misma -4 de febrero de 1563- y la identificación de los impresores autorizados también. La licencia otorgada a Antonio de Lebrija y García de Briones para imprimir los Quarenta cantos en Granada fue pues utilizada por Juan Millán en Zaragoza.

Lo mismo pasa con la edición de 1587, dotada de dos cartas que autorizan su impresión: una de fray Alonso de Villalba, del Carmen de Madrid, sin indicación de impresor, y otra del rey don Felipe que no se destina a Juan de Millán, sino a «Pedro Navarro, impressor de libros ${ }^{50} 》$. Es de interés observar en qué se fundamentan para autorizar la difusión de los Quarenta cantos de Alonso de Fuentes, en la medida en que hacen claramente eco a la epístola

\footnotetext{
${ }^{48}$ Son tres las formulaciones visibles en la portada: «con licencia» en la edición de 1550, «con licencia impresso» en las de 1563 y 1564, e «impresso con licencia» en la de 1587 . Tal vez encuentre alguna explicación en el hecho de que la palabra «Licencia» encabeza solo la carta del rey, no la de fray Alonso de Villalba.

${ }^{49}$ Menciona al final de la carta que «fue impresso en Seuilla. Siendo primero visto y examinado en el Collegio de santo Thomas de la dicha ciudad». La mención de la primitiva licencia remite al colofón de la princeps.

${ }^{50}$ Quarenta cantos, 1587, f. 2r.: «ninguno otro impressor lo pueda imprimir sin vuestro poder y licencia» (ibid., f. 2v). Deja abierta la posibilidad de un acuerdo entre el destinatario de la carta inicial y Juan Millán. Sin embargo, llama la atención el hecho de que no se mencione en ningún sitio de la obra ni como post-data a la presente carta real, la transmisión de la licencia.
} 
dedicatoria que el autor dirigió a Perafán de Ribera. El fraile declara, no sin cierta prudencia ${ }^{51}$ :

Por mandado de los señores del Consejo Real, he visto este libro intitulado de los quarenta Cantos: que compuso el cauallero Alonso de Fuentes, \&c. En el qual no ay cosa (a mi parecer) que sea en contra de lo que nuestra madre la Yglesia cree y confiessa. Antes me parece que de la impression nueva que se pretende resultara utilidad y prouecho para los ignorantes, y gusto y contento para todos los que con breuedad dessean saber hystorias, assi de la escriptura como de gentes barbaras: y este es mi parecer ${ }^{52}$.

Los temas subrayados figuran en el título desarrollado de las ediciones anteriores, y de la de 1587, así como la dimensión histórica del conjunto. Las dos clases de públicos evocados, los ignorantes y los que anhelan saber más sin dedicar mucho tiempo al estudio, ya están en filigrana en la carta dedicatoria del autor. De hecho, Alonso de Fuentes afirma en ella haber emprendido la escritura de los Quarenta cantos a petición de un señor que solicitó su ayuda para entender mejor una serie de textos de diversas historias, «por carecer de noticia de algunas dellas». La obra se puede comparar a la respuesta de un maestro a la petición de un discípulo ${ }^{53}$. En cuanto a la conformidad con el catolicismo, su afirmación suple la desaparición, a partir de la edición de 1563, del calificativo «moralizados». La carta del rey autoriza la nueva edición, a petición de un impresor que afirmaba que el libro «era vtil y muy prouechoso» y que había «falta del $l^{54} \gg$. Se subraya así la idea de que el saber es necesario, convicción defendida por Alonso de Fuentes en su anterior Suma de Filosofia natural ${ }^{55}$, y motor de la escritura de los Quarenta cantos.

${ }^{51}$ Es imposible no sentir la insistencia. En un texto corto, reitera en tres ocasiones la afirmación según la cual solo expresa su opinión; interrumpe su declaración con «a mi parecer» entre paréntesis; abre su segunda oración con «me parece que» y concluye reafirmando: «este es mi parecer».

${ }^{52}$ Quarenta cantos, 1587 , f. $1 \mathrm{v}$.

${ }^{53}$ No se pueden colocar en el mismo plano los fallos del señor que no supo entender bien todos los romances y las protestas de humildad de Alonso de Fuentes, cuando afirma que escribió el libro «no con poca dificultad» y que representará para Perafán un «pequeño servicio», concluyendo con la idea de que la grandeza del marqués es la única capaz de suplir lo que «el caudal de [su] entendimiento no pudo complir». Subrayando así los méritos del destinatario, invitado a ilustrar una sentencia de Plutarco, opta el autor por una muy conocida estrategia de captatio benevolentiae.

${ }^{54}$ Quarenta cantos, 1587 , f. 2r. No figura en la carta del rey ninguna opinión de tipo personal y se apoya la decisión de dar licencia en los expertos que examinaron el ejemplar entregado para pedir nueva impresión. La carta concluye con la enumeración de los letrados que participaron en el consejo real para aprobar la impresión, asociados con el escribano de cámara del Rey, los miembros del concejo y el chanciller mayor (ibid., f. 3r).

${ }^{55}$ El desarrollo de la Suma de Filosofia natural «se presenta como antídoto contundente (nada menos que el uso del verso, con alternancia de metros italianos y españoles en correspondencia con la cuna de los dos conversantes) a los que repudian las letras» según Rafael Malpartida Tirado, «Encantamiento del 
En conclusión, el examen de las portadas, de la carta dedicatoria y de las sucesivas licencias que acompañaron, entre 1550 y 1587, las cuatro o cinco ediciones de los Quarenta cantos comentados por Alonso de Fuentes, es un paso previo indispensable para apreciar el contexto editorial en el que la obra circuló por la Península. Revela la originalidad de una obra que participa de la moda del romancero a partir de mediados del siglo XVI, sin utilizar siquiera la palabra genérica en la portada, ni el formato del libro de bolsillo, ni el canon de las colecciones de textos para cantar. Dibuja la exigencia de un autor de honda cultura clásica, cuya ambición es combinar la fuerza de seducción del verso con la capacidad analítica de la prosa. No se identifica como autor de los romances, asumiendo así la tradición ya antigua del comentario, de la glosa, fuera de las prácticas recreativas de la corte o, mejor dicho, más allá de los versos que servían de compendios cómodos. El presente trabajo permitió llegar a primeras conclusiones que abren camino a un estudio más específico de la materialidad de la princeps de 1550: lejos de limitarnos a extraer del conjunto los versos romanceriles, analizaremos en otro trabajo cómo se estructura un sutil juego entre textos y contextos, cuya compleja regla encierra la epístola escrita por Alonso de Fuentes a un futuro lector ya difunto, a quien, según sus propias palabras, tiene «entendido que le diera gran contento ${ }^{56} \gg$.

Recibido: 24/01/2020

Aceptado: 1/05/2020

diálogo humanístico: la memoria y el olvido», en Humanismo y perviviencia del mundo clásico. Homenaje al Profesor Antonio Prieto, Madrid-Alcañiz, CSIC, 2008, t. 4:1, p. 334.

${ }^{56}$ Quarenta cantos, ob. cit., carta dedicatoria, f. 2r (1550, 1563 y 1564) y f. 3v (1587). 
Antes de Leer los QuaReNTA CANTOS De Alonso de Fuentes: PORTADAS, DEDICATORIAS Y LICENCIAS EN EDICIONES DEL SIGLO XVI

Resumen: Los Quarenta cantos de Alonso de Fuentes se imprimieron por lo menos cuatro veces entre 1550 y 1587 , y hasta cinco si se tiene en cuenta una edición de 1557 , de la que no se ha podido localizar ningún ejemplar. Sin que lo indique el título, participa de manera original al fenómeno editorial que permitió la afirmación del género romanceril. El estudio del peritexto y de la carta dedicatoria muestra que no derivan los cuarenta y cinco ejemplares conservados de un modelo único y que tampoco conectan con el canon editorial del romancero, que nace con el Cancionero de romances de 1546 . Ninguna de las portadas manifiesta un particular cuidado ni un diseño concreto único: más bien muestran cierta desenvoltura y reciclaje de materiales previos. Sin embargo, el estudio del peritexto confirma el interés renovado, a lo largo de la segunda mitad del siglo XvI, por una obra cuyas características apuntan a la vez a la tradición del comentario, a la moda del romancero, y a la originalidad de una glosa de romances en prosa, manifestando la entrada del Romancero en un círculo de letrados.

Palabras Claves: Romancero. Siglo Xvi. Alonso de Fuentes. Ediciones. Peritexto.

\section{Before READING the QuaRENTA CANTOS By Alonso de Fuentes: COVERS, DEDICATORY EPISTLES AND LICENSES IN 16TH CENTURY EDITIONS}

ABSTRACT: The Quarenta cantos of Alonso de Fuentes were printed at least four times between 1550 and 1587, and up to five if we include an edition of 1557, from which no specimen could be found. Without any relevant detail in the title, it participates in an original way to the editorial phenomenon that allowed the affirmation of the romanceril genre. The study of the peritext and the dedicatory epistle shows that the forty-five preserved copies are not derived from a single model and that they do not connect with the romance's editorial canon, which was born with the Cancionero de romances of 1546 . None of the covers shows a particular care or a unique concrete design: rather they show some development and recycling of previous materials. However, the study of the peritext confirms the renewed interest, throughout the second half of the 16th century, for a work whose characteristics point at the same time to the tradition of commentary, the fashion of the romance, and the originality of a gloss in prose of romances, manifesting the entrance of the Romancero in a circle of learned people.

Keywords: Spanish ballads. 16th century. Alonso de Fuentes. Editions. Peritext. 